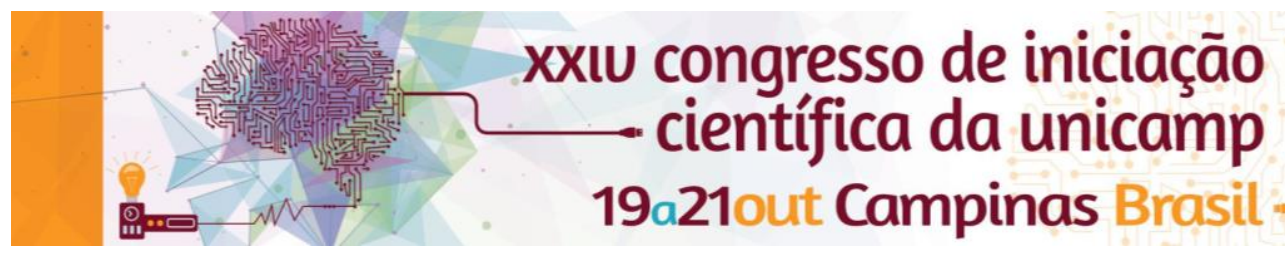

\title{
UEC-4, -5 and -6 silicoaluminophosphates with 3D-structures from a 2D- organoaluminophosphate
}

\section{Heitor S. Seleghini, Heloise O. Pastore.}

\begin{abstract}
Zeolitic structures can be synthetized in many ways, one of them is to use a layered precursor as source of T atoms ( $\mathrm{Si}$, $\mathrm{Al}, \mathrm{P}, \ldots)$ in the presence or absence of organic structure directing agent (SDA). In this work the possibility of using a layered aluminophosphate, with N,N-dimethylbenzylamine as SDA, in combination with another organic directing agent to create three new zeotypic structures UEC-4, -5 and -6 was studied.
\end{abstract}

Key words: 2D-to-3D transformation, Silicoaluminophosphate, Zeotypes

\section{Introduction}

The possibility of combining two SDAs in the synthesis of zeotypes have been studied using one SDA from a layered aluminophosphate and another SDA added in the synthesis reactor ${ }^{1}$.

The combination of $\mathrm{N}, \mathrm{N}$-dimethylbenzylamine from the AIPO-CJ702 with the addition of silica and tetraethylammonium, n-butylamine and hexamethyleneimine in a hydrothermal process creates three new zeotypes silicoaluminophosphate with structures analogous to SAPO-5, -15 and -35, respectively, were named Universidade Estadual de Campinas $-4,-5$ and -6 .

\section{Results and Discussion}

The powder XRD from UEC-4 (Figure 1a) shows a crystalline $\mathrm{AFI}$, the XRD from UEC-5 (Figure 1b) shows only the crystalline phase from the SAPO-15 analogous, and the XRD from UEC-6 (Figure 1c) shows a LEV phase but with SAPO-15 contamination.

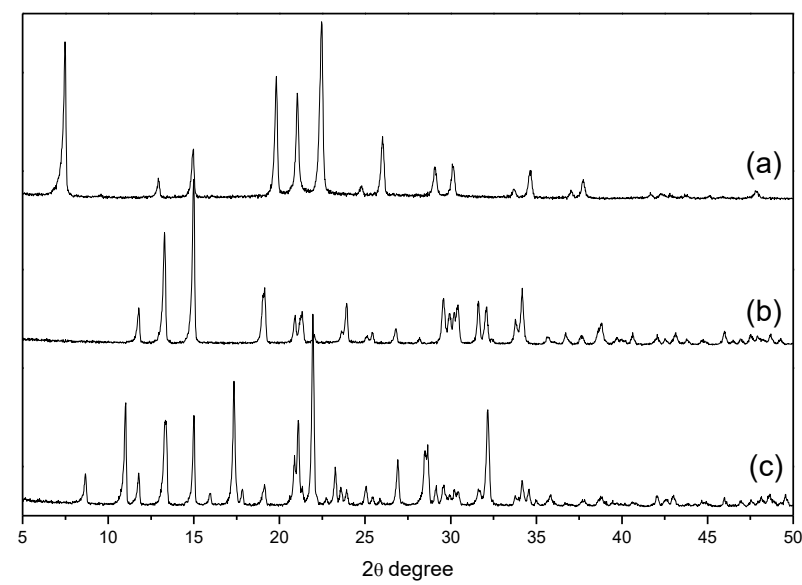

Figure 1. Experimental powder XRD from a) UEC-4, b) UEC-5 and c) UEC-6.

In the UEC-4 ${ }^{13} \mathrm{C}$ MAS NMR, peaks from tetraethylammonium (7.5 and $53.0 \mathrm{ppm})$ and $\mathrm{N}, \mathrm{N}$ dimethylbenzylamine $(41.5,62.0$ and $130.9 \mathrm{ppm})$ were observed. Their simultaneous presence means that both SDAs are working together to build the AFI-type structure of UEC-4. In the UEC-5 ${ }^{13} \mathrm{C}$ MAS NMR, the $\mathrm{n}$ butylammonium (11.3, 19.5, 36.3 and $46.4 \mathrm{ppm}$ ) added in the synthetic process causes the formation of the threedimensional structure of SAPO-15, because of the pore size of the UEC-5 and the synthesis temperature, the N,Ndimethylbenzylamine molecules may be expelled from the final structure or decompose during the hydrothermal process.

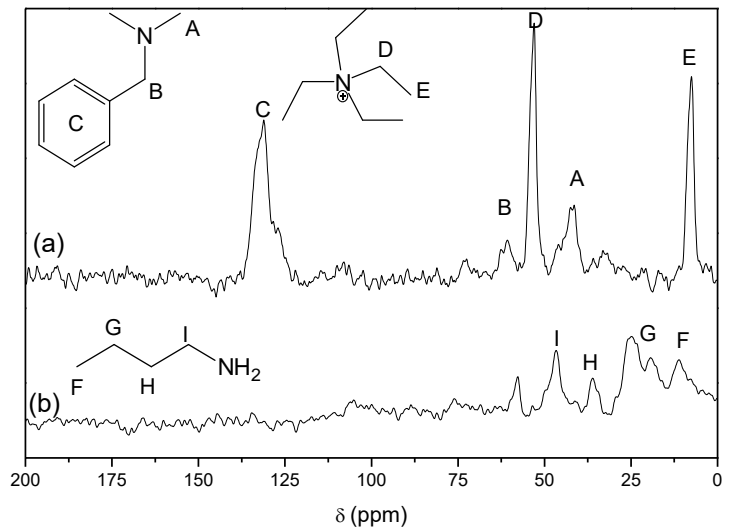

Figure $2 .{ }^{13} \mathrm{C}$ CPMAS NMR from a) UEC-4 and b) UEC-5.

Scanning electron microscopy was used to monitor the transformation of the lamellar AIPO-CJ70 to a condensed morphology. The signals of the layered precursor are still evident on the surface of the final crystals, indicating a clear 2D-to-3D transformation.

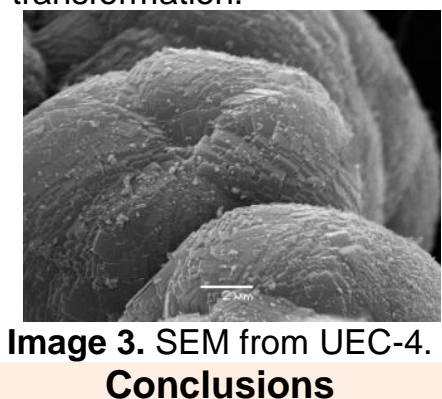

A new synthesis method to prepare AFI-type, SAPO-15 and LEV-type structures has been found, starting from a single source of $\mathrm{Al}$ and $\mathrm{P}$ in layered form. The $2 \mathrm{D}$ to $3 \mathrm{D}$ transformation is only possible because of the activation of the layered aluminophosphate by the addition of silica. The ${ }^{13} \mathrm{C}$ NMR indicated that both N,Ndimethybenzylamine and tetraethylammonium work together to build the UEC-4 structure, while the first decompose to form UEC-5.

\section{Acknowledgement}

FAPESP for the financial support. 2014/06942-0.

1) H. O. Pastore, G. A. V. Martins, M. Strauss, L. G., Pedroni, G.B. Superti, E. C. de Oliveira, G. Gatti, L. Marchese, Micropor. Mesopor. Mater. 2008, 107, 81.

2) J. Zhu, Y. Yan, J. Liu, X. Song, Inorg. Chem. Commun. 2015, 56, 133. 